\title{
Engagement of patients and the public in NHS sustainability and transformation: an ethnographic study
}

Pam Carter,

University of Leicester, England,

Graham Martin,

University of Leicester

\begin{abstract}
Internationally, debates are taking place about sustainable healthcare. In England, guidance on patient and public involvement (PPI) advocates' engagement' and references Arnstein's ladder of participation, but recent proposals provoked controversy around service closures and the perceived exclusion of patients and the public. This article reports an ethnography of engagement, prior to formal public consultation on plans for major service change. Our analysis uses Cultural Political Economy, linking micro interactions between staff and 'involvees' to processes of political economy. We found that co-optation and contestation both occurred. Involvees queried whether the forthcoming consultation was genuine or whether decisions had already been made but the issue of whether NHS services should be delivered by public or private bodies was kept off the agenda. We conclude that engagement in system transformation programmes implicates PPI in a neoliberal agenda that rations state support for healthcare and introduces service models from the US and elsewhere.
\end{abstract}

Keywords: discourse, health service change, political economy, public engagement, patient and public involvement. 
Introduction: citizen control, rhetoric and reality in contemporary healthcare

Arnstein's 'Ladder of Participation' (Arnstein, 1969) is one of the best known models of citizen involvement. This ladder moves from a bottom rung categorized as 'manipulation' to the top rung of 'citizen control'. Arnstein's 'adversarial' approach and reliance on a zero-sum model of power has been critiqued (Tritter and McCallum, 2006), but the model remains influential in academic, policy and practice circles alike. Like Arnstein, we have interests in citizen participation, applied health research and health policy. Unlike Arnstein, who worked in the United States, where health services are mainly funded by insurance and where access to healthcare is restricted, we are from the United Kingdom. While the NHS can hardly be constructed as an instance of Arnstein's 'citizen control', its creation did largely take health out of the market and provide citizens with universal entitlement to free healthcare. Since Arnstein's time, however, global policy developments have entailed neoliberal shifts in many welfare-state regimes that have reduced entitlement, increased use of eligibility criteria, and eroded democratic accountability. The Ladder of Participation is thus arguably more relevant now to public healthcare systems than when Arnstein developed it.

Despite shifts in the financing and provision of healthcare that have seen increasing privatesector involvement, the NHS retains a special place in the nation's symbolic imagination so that politicians are reluctant to be seen to be responsible for 'dismantling' its provision (Frith, 2016). At the rhetorical level at least, and in contrast to neoliberal shifts towards competition and markets, a 'commons' discourse (Ostrom, 1990) infuses the NHS Constitution, which claims that "the NHS belongs to us all" (DH, 2012). NHS England explicitly uses Arnstein's ladder in its overarching Patient Participation Policy (NHS England, 2015), albeit in truncated, adapted form. Here the top rung appears as 'Devolving', defined as "placing decision making in the hands of the community and individuals, "while Arnstein's bottom 
two rungs - 'manipulation' and 'therapy', associated with concepts derived from critical theory (Gibson et al, 2012, Barnes and Cotterell 2012, Hickey et al., 2004)—disappear altogether. While this adaptation arguably dilutes the radical implications of Arnstein's model that critiqued minimal or manipulative forms of PPI, use of the ladder nevertheless indicates the normative power offered by notions of 'our' NHS.

Recent reforms, however, have effected quite a different relationship between the NHS and its public. Many have argued that the 2012 Health and Social Care Act fundamentally alters the relationship between citizens, government, market providers and the users of services (Mattei et al., (2015). The NHS Five Year Forward View sets out a vision for transformational changes claimed to be necessary for the longevity of the NHS (DH, 2015) and highlights three gaps to be reduced or eliminated: the health and wellbeing gap; the care and quality gap; and the finance and efficiency gap. Critics have suggested that it is the third of these that has driven change efforts, most notably the recently introduced Sustainability and Transformation Plans (STPs) (Leys, 2016). Mandated by NHS England and NHS Improvement, STPs arrived in 2016 and were swiftly introduced with 44 local partnerships charged with producing plans to implement the Five Year Forward View Alderwick et al. (2016). Guidance stated that patients and the public should be engaged in developing STPs but initial reviews of their activity suggest that such efforts have been minimal: "To date public discussion of plans, or involvement in their development, has been limited" (Alderwick et al, 2016).

There is thus something of a gap between rhetoric and reality in the contemporary governance of the NHS, as public-facing documents maintain the narrative of public ownership and control of the service, while changes on the ground result in increasing fragmentation and attendant deficits in accountability (Martin et al., 2017). Our study seeks to examine how this tension came to bear on the activities of a group that found itself at a key 
nodal point within such debates: the patient and public involvement (PPI) group that formed a key part of the 'public engagement' process followed a regional healthcare transformation initiative. 'Engagement' is a relatively new term in the lexicon of citizen involvementunlike 'consultation', for example, the term does not appear on Arnstein's ladder-but it is a crucial phase in the formal process set out for major healthcare reconfigurations in England (see Figure 1). We explore how their role in developing the plan was structured, the extent to which they sought to assert their 'ownership' of the NHS, and the degree to which they accepted or challenged moves that might reduce accountability or increase private influence. With a view to understanding local engagement practices in the light of macro policy shifts, we draw on Cultural Political Economy (Sum and Jessop, 2013).

\section{Methodology: Cultural Political Economy}

Cultural Political Economy (CPE), as set out in Jessop (2010) and Sum and Jessop (2013), builds on a range of critical theorists, including Marx and Gramsci, complementing them with Foucauldian and discursive approaches. For sociologists, the value of CPE lies in linking materiality and semiosis and adopting a standpoint against oppression to incorporate Ideologikritik (Sum and Jessop, 2013: 343) into analysis. CPE links four elements: semiosis (meaning making), agency, technologies and structuration, and connects policy, discourse and material practices, offering a " 'third way' between a structuralist Scylla and a constructivist Charybdis" (Sum and Jessop, 2013:340).

Specifically, CPE focuses on problematization and depoliticization processes to examine how issues come to be perceived as matters for political contestation or alternatively as amenable to technical solutions. Such issues seem particularly pertinent in an NHS context where there is explicit acknowledgement of the importance of 'the narrative' surrounding the Five Year Forward View, and ensuring that this narrative is understood by and accepted by the public (Alderwick et al, 2016). A further example of CPE's use-value for critical policy studies is its 
examination of the relationship between discursive representations and structuration to understand shifts in 'glocal' health economies. Structurally, 'the NHS' has shifted away from a national system that guarantees equitable provision of universal healthcare based on need towards public and private organisations in various forms of collaborative, competitive and contractual relationships (Mattei et al., 2015). However, this understanding or 'construal' may not yet be apparent to or widely shared by patients and the public more familiar with the commons discourse of a national public service.

Connections between agents and organizational meaning making, practices and sociotemporal 'large-scale social formations' are elucidated thus by Jessop:

Attention to all four aspects and their interaction is required to explain why and how some construals are selected, get embodied/embrained in individual agents or routinized in organizational operations, are facilitated or hindered by specific social technologies and affordances, and become embedded in specific social structures ranging from routine interactions via institutional orders to large-scale social formations. (Jessop, $2010: 339)$

Importantly, CPE insists on limits to the fluidity of semiosis so that language is not infinitely malleable and ontologically, the world comprises more than words and signs. Construals may be more or less durable and consequential, depending on material practices and extrasemiotic conditions that include sedimented power relations, specific organizational forms and the spatio-temporal fixes of contemporary capitalist social formation. There are institutionally prescribed limits on language: certain words are performative and enact legislative processes that structure events. To give one example pertinent to our study, once a process is categorised as 'public consultation' rather than 'engagement', NHS organisations are bound by a set of principles and legislative requirements and there are legally enshrined 
provisions in relation to accessible information, minimum time to respond and so on (see Figure 1) (Kaehne and Taylor, 2015).

Complexity reduction is posited by $\mathrm{CPE}$ as a fundamental existential necessity that enables individuals to 'go on' in the world (Jessop, 2010: 337). But the way in which complexity is simplified has major implications for how policy is understood, enacted and reproduced. We were interested in how the complexity of transformation of the 'institutional order' of the NHS was enacted and how the routine work of the PPI group became an affordance - that is to say, "the possibilities of action ... offered by a given material object or social network" (Sum and Jessop, 2013: 9). Through our analysis, we seek to show what the PPI Group as a social network afforded or enabled (and what alternatives it prevented or curtailed) as it variously challenged or repeated discursive devices including metaphors, 'catch phrases' and 'mantras' that formed part of a contingent governmental technology.

\section{Methods}

We conducted research in one English region, using a two-phase study design. Phase one comprised a regional analysis; we gathered Joint Strategic Needs Assessments and Health and Wellbeing Strategies from local authority-based Health and Wellbeing Boards, as well as business plans from local Healthwatch bodies and conducted face-to-face semi-structured interviews with 32 representatives of these organisations. Our analysis of phase one data alerted us to the increasing prominence and importance of local 'transformational' plans in realising the objectives of the Five Year Forward View. We became aware of the disjuncture between, on the one hand, documentary data that indicated the assessment of need and production of strategy at a local authority level, with attendant accountability mechanisms of Health Overview and Scrutiny Committees and local Healthwatch, and on the other hand, 
interview data that suggested that strategic planning was taking place at a broader, supra-local authority level accompanied by opaque accountability mechanisms (Hudson, 2017). For phase two, we focused on the plans being developed in two regions that subsequently developed into Sustainability and Transformation Plans (STPs), and obtained ethical approval to study these through the Health Research Authority. This article focuses on one ('the Programme'), where permission was granted (on condition of anonymity) to observe a series of meetings of patients and the public who were engaged in the regional transformation programme ('the Group'). Data collection included 38.5 hours of observation of PPI meetings over a period of approximately six months, and 50 further interviews with a sample of NHS staff, patient and public participants, wider members of voluntary and community sector organisations, and Healthwatch representatives. Fieldwork was shaped over time by our interest in relating PPI to broader shifts in political economy. Theoretically our data analysis was influenced by CPE as outlined in our methodology section above and practically we used Nvivo software to apply a form of template analysis (King, 1988) whereby we developed an initial set of codes based on our knowledge of the literature on patient and public involvement. This coding framework shaped interview schedules and, in effect, tested out in deductive fashion what we expected to see in the data. Our analysis proceeded iteratively and as we generated novel themes inductively from the data, these were added to the initial coding framework. The production of policy relevant ethnography is recognised as a challenging process (Exworthy et al, 2010) but we have sought to provide a theoretically informed and reflexive account (Willis and Trondman, 2000).

What follows is a longitudinal reconstruction of events between early 2014 and late summer 2016, aimed at presenting analytically significant events as they unfolded. We present our findings as a chronological account moving from recruitment of participants, through 
development of the terms of reference for the PPI Group, to the emergent relationship between the Group and a wider public.

Getting engaged: representation, recruitment and selection

The PPI Group we studied could be understood as an 'invited space' (Cornwall, 2008), comprising lay people invited by NHS staff to participate in what was discursively portrayed as a comprehensive vision and partnership solution to the healthcare needs of the region through integration, efficiency and innovation. This case study area had a history of PPI activities, and this seemed to result in recruitment of 'the usual suspects', or 'professionalized patients' (El Enany et al, 2013, Thompson et al, 2012): individuals who had been involved in several similar ventures in the past. A local retired white man, with PPI experience, took on the interim task of chairing the complex transformation programme, which included NHS organisations and local authorities. Ring-fenced finance was initially available to fund the capital and one-off costs required to reorganise services, but there were ongoing challenges, including rising demand on hospitals, constrained resources and responding to the needs of diverse communities. The interim Chair created a PPI Group that met every two months for two hours in the daytime at a city-centre venue. As well as 'involvees', a Communications Director, a Communications Manager, the Programme Director, Project Manager and administrative staff all regularly attended PPI Group meetings, taking an active role in discussions.

Representation is a contested concept (Martin, 2008). The ethnic background of most involvees appeared to be white British; most were retired, and indeed needed to be, given the scheduling of meetings during the daytime. Fieldnotes and interview data indicated that Communications and Engagement staff who attended the Group were well-versed in diversity legislation, but it was unclear whether diversity within the Group was monitored. 
Periodically, involvees expressed concerns about their relationship to a wider public.

Fieldnotes record one raising the issue of responsibility for Programme outcomes and being 'judged': "what's worrying me is the outcome of this. Outcomes, and who are judged to be the representatives of the people." Several involvees were nominated to contribute to specific workstreams of the Programme, acquiring the role of, for example, 'Mental health PPI lead' or 'Long-term conditions lead'. This nomination and title transformed 'ordinary' (Martin, 2008) people into 'leads' who, as the above quote indicates, were somewhat reluctant to be held to account — 'judged'— but were willing to contribute their time and patient experience. Alongside nominations from the Group, however, recruitment to some workstream PPI activity took place via clinicians' own networks, thus bypassing and disempowering the PPI Group, despite its nominal position as the key conduit for PPI in the Programme.

Several involvees had multiple affiliations (Kerr et al, 2008), not all of which were publicly acknowledged. CPE attends to processes of selection and depoliticization (Sum and Jessop, 2013, Jessop, 2010), whereby issues are cast as technical, rather than as matters for contestation. Although more than one involvee belonged to a campaign group that supported public rather than private provision of healthcare services, this 'counter-public' (Gibson et al, 2012) was discursively sidelined within the Group. At one meeting campaigners were referred to pejoratively as "that banner-waving lot," and dismissed as "not truly representative” (fieldnotes).

The original Chair was replaced by a retired former hospital chief executive who was capable of scrutinising technical aspects of plans. While several involvees had knowledge of health and social care systems, others did not. One indicated his understandable but erroneous belief that 'the NHS' was a single organisation (Mattei, et al, 2015). Fieldnotes indicated a reluctance by Group members to put themselves forward for the position of Chair but after 
about 12 months, an open recruitment process enabled a further replacement Chair who was appointed by staff (rather than elected by the group) and remunerated by the Programme.

Contemporaneous documentary sources show that, despite ambiguity around representation, the phrase continued to be used. Minutes of an early PPI Group meeting record that two members were thanked for their involvement in a 'care services contract' and noted: "Representatives have signed a confidentiality agreement as elements are commercially sensitive." In interview, an involvee explained their involvement in developing this contract: It is very much on the American model: why are people still going to acute hospitals? ... I was part of the planning of this. ... It has got a seven-year contract. ... It is about the left-shift, it is about saving money—-that isn't the prerequisite-but it is about offering services in a different way in a blue sky thinking.

This involvee 'embrained' (Jessop, 2010: 339) the discourse of cost saving as an inevitable consequence of efficiency rather than as the primary rationale ("that isn't the prerequisite"). The emphasis on US 'policy imports' (Malone, 1999), financial savings and reduction in acute hospital services are embedded within the Five Year Forward View, but contracts and outsourcing (Bowman et al, 2015) were largely kept off the Group's agenda.

To summarise, involvees had varying levels of awareness and experience of complex NHS systems and transformation strategies. Some unwillingness to lead or to be accountable structured and constrained their activity, and their roles within the Programme were more akin to volunteers providing assistance than equal co-producers or a source of independent challenge. Despite a local tradition of well-networked PPI, expectations of confidentiality weakened involvees' status as representatives connected to broader communities. 
Terms of engagement

CPE takes agency and meaning-making seriously and builds on Foucault who showed how subjectivities are produced and constrained by power embedded in informal practices and routines as well as formal rules. The PPI Group adopted an informal meeting style that rarely recorded clear decisions (Ayres, 2017). A process of mimesis occurred whereby PPI Group documentation adopted templates such as an 'action-log' used by the Programme Board. These bureaucratic artefacts (minutes, agendas, action log) presented a business-like image but the more casual meeting culture constituted a practice of 'informal governance' (Ayres, 2017). There was no specified term of office for involvees and confusion about PPI in workstreams meant that who was entitled to be a Group member, what their obligations were and under what circumstances they might leave were all unclear. At one meeting the Chair reflected:

I am sure we've all been on committees where individuals cause trouble so we need to bite the bullet and have a clear mechanism so anyone turned down [as an involvee] knows the appeal process. My experience on committees has taught me there can be problems. (fieldnotes)

This acknowledgement of possible contention was, however, usually glossed over as meetings operated with an informal culture of apparent consensus, described by the Programme Director as 'a group of friends' (fieldnotes). Internal processual issues dominated many meetings and the Group reviewed its terms of reference three times within two years. The following are extracts from terms of reference that again refer to representation:

\section{The role and purpose of the PPI group}


Ensure views of service users, patients, carers and the public are represented by working in partnership with social care and health commissioners, in line with national policy.

\section{Decision making and delegated powers}

The Group is advisory and has no decision-making powers. It does however have sign off responsibilities. The advice and views of the Group will be reached by consensus wherever possible. Where consensus cannot be achieved, minority opinion will be noted and communicated.

\section{Confidentiality}

There will be occasions when selected information must not be disclosed outside the [Group].

The meaning of 'sign off' was unclear. Involvees had no formal authority in relation to the Programme: they had no power of veto, and Programme staff were under no obligation to take account of the views of the Group. Nonetheless, as CPE would anticipate, they exerted agency and sought influence. Fieldnotes record how some involvees were familiar with the statement "nothing about me without me," and had sought to deploy this empowering slogan to increase their influence. At one meeting the group challenged the need for confidentiality and the Programme Director attempted to explain: "I will respond to confidentiality. Legally if you tell a small group of people then the potential consultation can be challenged before it starts, so that's the reason. I know some of the stuff there is emotive and sensitive. We have to have a proper conversation and not before, or people who are impacted could feel abused and offended" (fieldnotes). This "proper conversation" referred to the forthcoming formal public consultation that carried legal implications and was acknowledged as potentially contentious (cf. Figure 1). 
Foreshadowing a narrative of managing demand through 'self-care', minutes note that: "significant self-care education and prevention will require PPI engagement as this is where resistance will be." This reference to anticipated 'resistance' indicates that staff were alert to potential opposition to 'sensitive' aspects of the transformation proposals, including 'selfcare', and sought the Group's assistance in broaching these.

The politics of wider engagement

While 'consultation' appears around the middle of Arnstein's ladder, the term 'engagement' does not feature. In the context of the Programme, it denoted the period of more informal involvement of the public prior to formal, legally required consultation. Moreover, appropriate engagement with the public is one of four tests, known as the Lansley tests (Barrett and Raine, 2012), that English transformation proposals must be judged to have passed prior to approval to proceed to formal consultation (see Figure 1).

The PPI Group was seen as part of this engagement process, and was also asked to assist with the Programme's efforts to widen engagement to the wider public. It could not itself represent the wider public in any political or statistical sense, but the Group functioned as a 'minipublic' (Goodin and Dryzek, 2006); in CPE terms, as an 'affordance' for staff to test out the language the Programme might use when communicating with a broader public and assess the interpretations (construals) that might follow in the course of the formal consultation. The Group was asked to assist with a public engagement and awareness campaign. The campaign was light on detail and like other STPs was presented in vague, general terms, as "a plan for a plan" (Edwards, 2016). The campaign may have been perceived by the wider public as 'consultation', since views were sought. For example, the campaign questionnaire asked (somewhat rhetorically) whether people should take responsibility for their own health. The campaign contained no detailed financial information or any acknowledgement of 
distinctions between for-profit or not-for-profit service providers. Nevertheless, the report that followed the campaign claimed that there was public support for the "broad direction of travel," thus constructing public endorsement for the vague plan in advance of the formal consultation on the more detailed specifics. Metrics used in this report included questionnaires, website visitor numbers, Twitter "impressions" and "over 100 conversations" at a conference. These engagement metrics formed what CPE might recognise as a 'technology', a 'meaning-making instrument' (Jessop, 2010).

Following the information campaign, staff became aware of the risk of over-reliance on the PPI Group to satisfy external expectations of the engagement process. At one meeting where terms of reference were being debated yet again, a Communications manager said: "I'm worried now-I need a life vest. Someone could challenge: this could look like a cartel" (fieldnotes). The term 'cartel' carries negative connotations of exclusivity and to address concerns about the restricted nature of the PPI Group, greater involvement was sought from local voluntary organisations. The issue of representation re-surfaced as discussions took place about governance and the relationship between the Programme and its various 'stakeholders'.

Two meetings were held to address how the voluntary, community and faith sectors might engage with the Programme. Fieldnotes highlight a tone very different from the consensual culture of the PPI Group, with individuals from several of the organisations represented sensing that they were being excluded or that the Programme was not taking their input seriously. The Programme Director delivered a presentation, whereupon a user-group representative complained vociferously because mental health was excluded; another man threatened to walk out of the meeting. This type of tension was alluded to later by a Communications Director who remarked: "Someone once told me that PPI was a full contact 
sport." On this occasion the tension in the room was diffused with humour as a staff member commented: "I will take away [the question of] how do we communicate? There is a huge programme. Excuse me while I put my teeth in!" Conciliation through the agency of this diplomatic manager enabled the meeting to proceed without further antagonism but structurally, the Programme's relationship with this wider constituency remained unfinished business.

A Communications officer summed up and remarked: “Today's event takes an officer half a day so we could do things by email" in future (fieldnotes). This managerialist comment highlights the material resources required and the range of possible methods or technologies (Rowe and Frewer, 2000) that might be encompassed by 'engagement'. It also highlights the distance between the rapid communication of predetermined information to disseminate a hegemonic narrative preferred by Programme officers, and emancipatory, dialogic methods that might enable citizens to structure the terms of the debate (Davies, 2011). Sum and Jessop (Sum, Jessop 2013) devote considerable theoretical attention to hegemony and counterhegemonies (p.206) that we do not have space here to fully engage with. Our analysis suggests, however, that staff negotiated a delicate balance between seeking to evidence support from 'engaged' patients and the public for the hegemonic Five Year Forward View 'direction of travel', while avoiding any suggestion that forthcoming public consultation might be a foregone conclusion, as this could trigger a judicial review that would delay progress and potentially derail transformation plans (Figure 1).

Co-creating the narrative? The PPI Group's role in preparing for public consultation The PPI Group was invited to an event arranged to share the Programme's vision with local clinicians but involvees were positioned in the audience, not invited onto the platform. The event, closed to the wider public, was chaired by a senior doctor who addressed the audience from a podium: 
The story so far is the Programme has a vision found up and down the country and in international models. Do nothing is not an option, so this is almost a call to arms. Smaller and more specialised is a catch phrase; [the local acute hospital's] footprint needs to shrink.

The catch-phrase reinforced and replicated the discourse and messages of the Five Year Forward View; paradoxically, fewer hospital beds was presented as a solution to the problem frame ( Jones and Exworthy, 2015) of 'relentless demand'. A leading figure from a national think-tank then gave a presentation and advocated:

Let's cut through the you-know-what. The best is from Kaiser Permanente. They have much lower bed use than the NHS. We're talking increasingly the same language. (fieldnotes)

Kaiser Permanente is a California-based managed care consortium. Although there is no evidence that lower hospital bed use can be achieved in the UK without compromising outcomes for patients (Ruane, 2016), the spokesperson from the internationally renowned think-tank promoted this example and positioned herself in this strategic site as a 'straight talker', pre-empting accusations of 'spin' (Peters, 2016). We see in such discursive manoeuvres key ways in which policy construals start to take hold; as Jessop puts it:

The greater the range of sites (horizontally and vertically) in which resonant discourses are retained, the greater is the potential for effective institutionalization and integration into patterns of structured coherence and durable compromise. (17) (p. 341).

A further means of refining the narrative to be put forward in the public consultation was a 'lock-in' held over two days. Minutes record that 'the lock-ins confirmed the key points of the 
programme for public consultation'. In interview, an involvee who had been excluded from this process commented:

Lock-ins-they said, "Oh, well, you know, it wasn't really for you”: it was more for clinicians or something. So you think, sometimes they want input and other times they don't. These lock-ins and things: very, very undemocratic. They didn't say, "Do you want to come?" They just said certain people are going. I think, for a lock-in, three people [are] going [from the PPI Group].

Another member who had been invited described her experience:

I went to a lock-in as the patient voice about that and although it was a load of highly confidential stuff, basically what they were saying is what we're going to move and what we're going to have to close down.

'Invited spaces' thus entailed inevitable exclusion of certain publics (Carter, 2016, Carter and Martin, 2016). The discursive negotiation that took place resulted in a written text, a PreConsultation Business Case (PCBC). The ability to critique the PCBC was further constrained, as the document was not circulated electronically to the PPI Group; rather, involvees were invited to view the several-hundred-pages-long text at the Programme office.

First of all, we were not allowed to see it, then it was agreed that if we went into the office in [the city], we could read it under supervision.

We had to go in, and sit there and read it, and I'm not a fast reader [laughs], took me a long time, but you start to think, where's the funding for the likes of the hospital at [Antville]? So the decision's been made.

Within the Group there was unease about proposals. Hospital 'closure' was discursively represented as 'reconfiguration' (Jones and Exworthy, 2015) by communications staff and 
others but in one meeting an involvee expressed their need for and expectation of 'honest' communication:

It worries me about the closure of [Antville Community Hospital]. The Programme Director objected to 'closure'. It's the people in that area that are going to be so angry - [the Programme] do need to be honest. (fieldnotes)

Another involvee noted a local hospital was displaying a for-sale sign. In CPE terms this might be understood as the 'co-evolution of the semiotic and the extra-semiotic' (Jessop, 2010: 337). The narrative for public consultation construed hospital closure as 'transformation' but land values seemed to be informing decision making. The for-sale sign suggested to this involvee that a decision to close it had already been taken and therefore that the forthcoming consultation was dishonest rather than meaningful.

Two senior Programme officers took time to attend a Group meeting. The PPI Chair endeavoured to put staff and involvees at ease and framed the encounter as an informal "tea and biscuits" meeting (fieldnotes). The Chief Officers wanted to know the Group's views and one said:

Discussions about banana skins is exactly what we want from you. Honest conversations, plus point out banana skins to us.

This metaphor referred to expectations that the Group would demonstrate to staff where they might be 'tripped up' when plans went to public consultation. The Group was thus positioned instrumentally in terms of its potential contribution to the reception (construal) of the Programme by the wider public, rather than in terms of independent critique or influence on the content of the plan. The Communications Director listed 'hot topics', including a community hospital: "We want [Beeville] Hospital to close - hardly anybody uses it" 
(fieldnotes). In interview a Group member explained her concerns that closure of this hospital was a foregone conclusion:

I live in [Beeville]. And, you know-we're confidential here, aren't we? I know that that is going to close, as an inpatient facility. ... And then, you know, it matters to such a lot of people to get it right. It's going to impact enormously, isn't it? Moving things out into the community is a great idea, but to try and do it without any money to prime the pump. The nature of savings and where the cuts come, and where clinics are located is going to matter to a lot of people.

This involvee construed hospital closure as a foregone conclusion and challenged how cuts could be equated with efficiencies, but involvees' discursive efforts appeared powerless to influence closure plans. Reflecting the complexity of the moving plan and the significance of materiality, minutes from the meeting with the senior officers record: "the group needs to recognise that financials are constantly changing."

Chief Officers were preparing to report to a decision-making panel and at short notice the Group was asked to provide a letter that would evidence engagement to the national authorities charged with judging whether the Programme had passed the Lansley tests. The Communications Director explained:

We are going to be up in front of the beak on Monday, 'cause nothing scares NHS mandarins more. So they want to pressure test how much crap they'll get from the media. Someone will ask the question, "Do you think you have done a good job?" (fieldnotes)

The Communications Director stayed in the room while a discussion ensued about whether the Group could or should provide such a letter of 'assurance' at short notice, confirming whether a good job had been made of PPI. The Director explained: 
I don't want to write it. I suggest its coming from [PPI Group Chair]. It may say things like you're not sure about integration of PPI and the inconsistent depth of engagement - individuals on workstreams may have that view.

It was evident, however, that within the Group, exactly what such 'assurance' might mean was unclear. An involvee asked: "Is it assuring is it in the patients' best interests?" The Chair replied: "There are a number of interpretations around the word assurance. Time is too short now. The next agenda item" (fieldnotes). As usual, no vote took place, further deliberation was prevented and the matter was left hanging.

In advance of the decision meeting, three involvees communicated their concerns in an e-mail to the group. A letter was addressed to NHS England, explaining that members were largely satisfied with the PCBC and workstream activity, but that they were concerned about the confidentiality requirement. The letter also challenged the 'efficiency-through-integration' narrative: "The [Group] is deeply concerned that there is much less than essential progress in achieving partnership with local authority social care because this can threaten the delivery and success of the plans." The approval panel met but there was no evidence that the Group's challenge had been taken into account.

Thus for involvees, the complexity of a shifting situation, in which financial information was inaccessible and workstream PPI activity was difficult to manage, compounded inevitable power-knowledge asymmetries between involvees and staff. Rather than citizen-control or co-production, both staff and involvees appeared to be muddling through a 'web of interlocution' (Jessop, 2010 :p.347) at a particularly turbulent juncture in NHS transformation. 
Towards public consultation

Guidance on PPI in STPs was published at a late stage (Alderwick et al, 2016). A communications officer remarked, "It often feels like government is writing the guidance behind us, " and conveyed her sense of crisis management:

It's like trying to fix the plane while it's still in the air and travelling at 500 miles per hour. The pace of change. ... This time it feels like we're throwing the track down ahead of us. (fieldnotes)

Meanwhile, involvees voiced concern about a proliferation of PPI activities in parallel to the work of the Group, in a way that risked duplicating their own activity or undermining the Group's claim to be the primary conduit for public involvement ahead of formal consultation: I was at a meeting ... and found out [related group] had appointed their own PPIthey are doing their own thing... This new development could be seen as going in different directions. PPI reps and organisations don't know what the accepted conduits are. Groups are making decisions separately.... Who's making the decisions? (fieldnotes)

The PPI Group was one local ‘stakeholder' group among many, including Healthwatch and other groupings with a claim to speak for the public (Carter and Martin, 2016). Equally, it was becoming apparent that local decisions were being heavily structured by national-level authorities - and this contributed to a sense that the activities of the Group were counting for little in terms of influence on the content of the plan and the direction of travel of the Programme. When at a later meeting, the Programme Director conveyed the news that the Programme would be overtaken by the STP, an involvee expressed frustrations:

Ifeel ... the [Group] has been marking time. We don't discuss anything much. Maybe because the whole [Programme] is marking time with NHS England. It's never really 
clear. ... It's constantly shrouded in secrecy. We looked at a draft of the business case but we mustn't breathe a word. ... Although we are supposed to be representing the public we can't talk to them. ... What's clear is there will be a public consultation. I'd really like to know the timetable. (fieldnotes)

The Director responded vaguely: "it's a long way away." She delivered a brief presentation and invited questions. Recognising the imposed power of the STP, one member asked: "What about the timescale? I know the STP is going to get the whip out." The Director responded: "Delivery of the STP is over five years. Me and the chief executives met yesterday eveningthere is a greater sense of urgency than a group of friends." The same man asked: "When's it going to consultation?" Pressed for further detail, the Director commented, "You have to let the system do its job, " and reiterated the financial imperative that was being imposed from above: "The system is now being told you have to make sure you're delivering your STP and get in [financial] balance."

Following the completion of fieldwork, there were indications that, like other areas, the STP was struggling to agree a coherent financial plan in the face of these hierarchically imposed constraints (Edwards, 2016). Mainstream media began to report STPs, and controversial issues, such as insufficient hospital beds, increased demand on emergency services and on general practice, began to surface (Alderwick et al, 2016).

Discussion / conclusion

Legitimate participation may be in the 'eye of the beholder' or the involvee (Irwin et al, 2013) and several involvees explained in interviews that they felt they had made useful contributions, that their involvement had been respected, and that they trusted the staff they encountered. While some members took pride in the Group, others expressed frustration with a lack of control over a timetable, being excluded from certain meetings, discomfort at the 
requirement for confidentiality and disquiet over the 'direction of travel', including the framing of hospital closures as 'transformation'. However, what our CPE methodology helps us to uncover is not only individual perception and local micro-interactions, but also how these connect into "macro-social issues such as hegemony, domination, state power, or capital accumulation" (Jessop, 2010) that may take place "behind the backs of agents" (p. 338).

In our introduction we noted political reluctance to be seen to undermine the symbolic imaginary of the NHS. Policy rhetoric stating "the NHS belongs to us all" (DH, 2013)resonates with Arnstein's top rung of 'citizen control' (Arnstein, 1969), but despite this discourse of public ownership, early reports on STPs found a lack of political involvement (Alderwick et al 2016) and that "Patients and the public have been largely absent from the STP process so far” (Alderewick et al, 2016:5). In contrast, our ethnography provides an example of active involvement in one STP — but demonstrates how the scope, boundaries and contribution of this involvement were shaped by macro-level preoccupations with financial savings and, arguably, by a direction of travel for transformation that had already been largely determined.

Perhaps because of a Habermasian tendency towards emphasising dialogue, consensus and collaboration, academic literature on involvement gives limited attention to the challenge of resolving difference (Martin, 2011, Mouffe, 1999), but beneath the apparent consensus of the 'group of friends' culture, dissent bubbled and the micro-politics of PPI were characterised as a 'full contact sport'. The Group's terms of reference permitted no formal means of resolving difference. Communications and engagement staff, trained in marketing, demonstrated little awareness of user-survivor movements (Barnes and Cotterell, 2010) or empowerment, as the contentious encounter with wider voluntary sector groups showed. The disparate views of members who may have either supported or campaigned against the imposition of new 
models of healthcare went unrecognised as consensus became a form of governmentality, reinforced through the ritual of tea, biscuits, humour and non-decision making practices (Ayres, 2017). Thus, as Alderwick et al. found, "difficult decisions [were] easy to avoid" (Alderwick et al, 2016: 25).

The Group's lack of veto and formal status within the governance of the Programme did not, however, equate to complete impotence or lack of influence. The proliferation of PPI highlighted the polycentric governance (Martin and Carter, 2016) that both weakened accountability (as it was unclear what the channels for influence were) but also, as CPE would suggest, was productive in providing involvees with access to information and new spheres of influence. Staff were aware of involvees' social capital and their contacts with Healthwatch, patient groups and campaigning organisations. Despite some degree of local mutual dependency, however, the Programme was increasingly forcefully managed, structured by NHS England and NHS Improvement (Alderwick et al, 2016), intent on imposing the Five Year Forward View with budgetary targets discursively framed as 'efficiencies'.

CPE insists that complexity reduction is inevitable. The slogan "Nothing about me without $m e$," harnessed by some involvees to bolster their claims to a legitimate right to influence the Programme, contradicted the Director's "let the system do its job”; these contrasting reductive statements exemplified tensions at the heart of PPI and citizen participation. Distinguishing issues that are technical and belong within an administrative system from issues that should be debated and decided in public is itself a political and ethical endeavour $(44,45)$. Our CPE analysis extends Arnstein's ladder to surface and problematize competing discourses of marketing and citizen accountability that are enfolded within 'engagement'. The instrumental 'evidencing' that engagement had taken place and complied with the requirements of the Lansley tests; the ambiguous remit of the PPI Group; the agenda framing; 
the exclusion of counter-narratives; the deliberate lack of transparency within the STP process: all of these lead us to conclude that the Ideologiekritik of Arnstein's ladder is still relevant. Arnstein's ladder was developed in relation to particular US policies and we argue that any assessment of PPI or citizen involvement should pay due attention to context: what involvees are engaged or participating in is critical. Our CPE analysis shows that at this key juncture, involvees were participating (partly knowingly, partly in ways that were concealed from them - "behind the backs of agents" (17) (p 338) in radical transformation of the NHS. The PPI Group we observed did this not, as a Habermasian analysis might suggest, through careful deliberation of alternative options with access to training, support and financial information, (Davies et al, 2006) but by helping communications and engagement staff to identify contentious topics and through discursive enrolment ('sign-off') into the local version of the Five Year Forward View.

\section{Acknowledgements}

We are grateful to the participants in this study, to our PPI group for their advice throughout the study and to the anonymous peer reviewers whose helpful comments and questions improved the final article.

This research was funded by the National Institute for Health Research (NIHR) Collaboration for Leadership in Applied Health Research and Care East Midlands (CLAHRC EM). The views expressed are those of the authors and not necessarily those of the NHS, the NIHR or the Department of Health. 

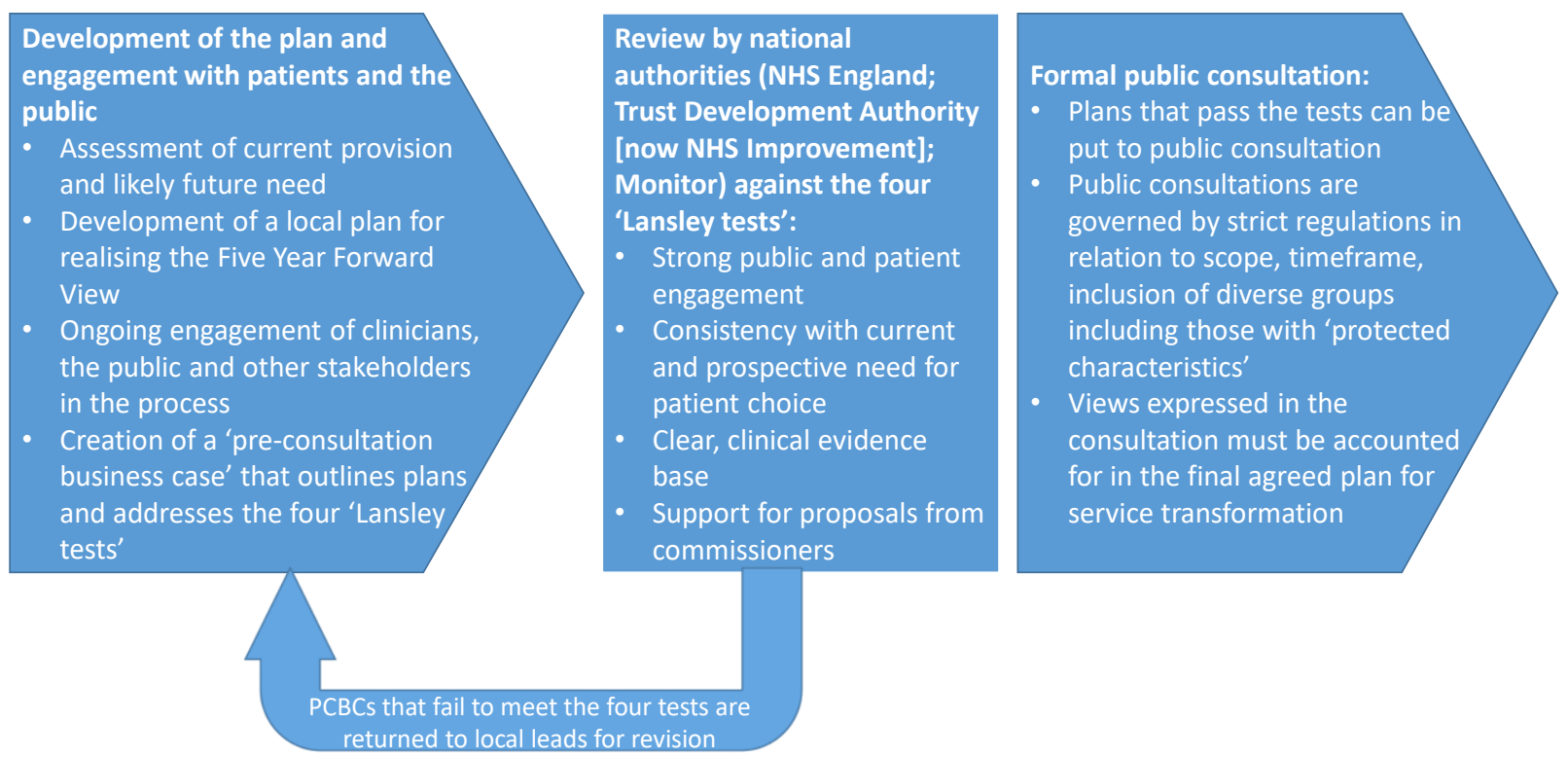

Figure 1: The relationship between the development of transformation plans, engagement, and formal consultation (adapted from Barratt and Raine 2012; NHS England 2015)

\section{References}

Alderwick H, Dunn P, McKenna H, Walsh N and Ham C (2016) Sustainability and Transformation Plans in the NHS: How are they being developed in practice? London: King's Fund.

Arnstein SR (1969) A ladder of citizen participation. Journal of the American Institute of Planners 35(4) 216-224.

Ayres S (2017) Assessing the impact of informal governance on political innovation'. Public Management Review 19 (1):90-107.

Barnes M and Cotterell P editors. (2012) Critical Perspectives on User Involvement. Bristol: The Policy Press.

Barratt H, Raine R. (2012) Hospital service reconfiguration: the battle for hearts and minds. BMJ British Medical Journal (online) 344.

Bowman, A, Ertürk, I, Folkman, P, Froud, J, Haslam, C, Johal, S, Leaver, A, Moran, M and Tsitsianis, N (2015) What a waste: Outsourcing and how it goes wrong. Oxford University Press.

Carter P (2016) Governing spaces: a multi-sited ethnography of governing welfare reform at close range and at a distance. Critical Policy Studies Sep:1-21.

Carter P, Martin G. (2016) Challenges facing Healthwatch, a new consumer champion in England. International journal of health policy and management 5(4):259

Cornwall A (2008) Unpacking 'Participation': models, meanings and practices. Community Development Journal 43 (3):269-283.

Department of Health (2012) NHS Constitution - the NHS belongs to us all. DH London (United Kingdom). 
Davies C (2011) Participatory Citizens - Desirable? Possible? Practical? Sociology 45(6): 1134-1139.

Davies C, Wetherell M, Barnett E (2006) Citizens at the Centre: Deliberative participation in healthcare decisions Bristol: Policy Press.

Department of Health. NHS Five Year Forward View. 2015; Available at:

http://www.england.nhs.uk/wp-content/uploads/2014/10/5yfv-web.pdf. (accessed 20 May, 2015).

Department of Health (2013). The NHS Constitution for England. London: Department of Health.

Edwards N (2016) Sustainability and Transformation Plans: What we know so far. London: The Nuffield Trust.

El Enany N, Currie G and Lockett A (2013) A paradox in healthcare service development: professionalization of service users. (80) :24-30.

Exworthy, M., Frosini, F., Jones, L., Peckham, S., Powell, M., Greener, I., Anand, P. \& Holloway, J. (2010). Decentralisation and performance: autonomy and incentives in local health economies. NIHR-SDO Progra Exworthy, M., Frosini, F., Jones, L., Peckham, S., Powell, M., Greener, I., Anand, P. \& Holloway, J. (2010). Decentralisation and performance: autonomy and incentives in local health economies. NIHR-SDO Programme Project $(08 / 1618 / 125)$.

Frith L (2016) The changing face of the English National Health Service: new providers, markets and morality. British Medical Bulletin 119 (1): 5-16.

Gibson A, Britten N, Lynch J (2012) Theoretical directions for an emancipatory concept of patient and public involvement. Health 16 (5): 531-547.

Goodin RE and Dryzek JS (2006) Deliberative impacts: the macro-political uptake of minipublics. Politics \& society 34(2):219-244.

Hickey S and Mohan G (2004) Participation: from tyranny to transformation? Exploring new approaches to participation in development. London: Zed books.

Hudson B (2017) Citizen accountability in the 'New NHS' in England. Critical Social Policy $1-10$.

Irwin A, Jensen TE and Jones KE (2013) The good, the bad and the perfect: Criticizing engagement practice. Social Studies of Science 43(1):118-135.

Jessop B (2010) Cultural political economy and critical policy studies. Critical Policy Studies $3(3-4): 336-356$.

Jones L and Exworthy M (2015) Framing in policy processes: A case study from hospital planning in the National Health Service in England. Social Science \& Medicine (124):196204.

Kaehne A and Taylor H. (2015) Do public consultations work? The case of the Social Services and Well-being (Wales) Bill. Public Policy and Administration (31)1: 80-99.

Kerr A, Cunningham-Burley S and Tutton R (2007) Shifting subject positions: experts and lay people in public dialogue. Social Studies of Science 37:385.

King N. (1988) 'Template Analysis' in Qualitative Methods and Analysis in Organizational Research a Practical Guide. Symon G Cassell C. eds, London: Sage Publications Ltd 
Leys C (2016) Can Simon Stevens' Sustainability and Transformation Plans save the NHS? Centre for Health and the Public Interest. https://chpi.org.uk/publications/analyses/cansimon-stevens-sustainability-transformation-plans-save-nhs/ (accessed 1 June 2017)

Malone RE (1999) Policy as product: morality and metaphor in health policy discourse. Hastings Center Report 29(3):16-22.

Martin G P, Carter, P and Dent M (2017). Major health service transformation and the public voice: conflict, challenge or complicity? Journal of Health Services Research \& Policy, DOI:10.1177/1355819617728530.

Martin G (2011) Public deliberation in action: Emotion, inclusion and exclusion in participatory decision making Critical Social Policy 32 (2):163-183.

Martin G (2008). 'Ordinary people only': knowledge, representativeness, and the publics of public participation in healthcare. Sociology of health and illness; 30(1):35-54.

Mattei P, Christensen T and Pilaar J (2015) Conflicting Accountabilities in the 2012 Health Care Reforms in England. International Journal of Public Administration 38(7):461-472.

Mouffe C (1999) Deliberative democracy or agonistic pluralism? Social Research: Oct.1 745758.

NHS England Public Participation Team (2015) Patient and Public Participation Policy; 04414.

Ostrom E (1990) Governing the commons: The evolution of institutions for collective action. Cambridge: Cambridge University Press.

Peters BG (2016) Governance and the media: exploring the linkages. Policy \& Politics 44(1):9-22.

Rowe G and Frewer LJ (2000) Public participation methods: A framework for evaluation. Science, Technology \& Human Values 25:(1)3.

Ruane S (2016) Market reforms and privatisation in the English National Health Service/Mercado reforma y privatización en el Sistema Nacional de Salud inglés. Cuadernos de Relaciones Laborales 34(2):263.

Sum N and Jessop B (2013) Towards a cultural political economy: Putting culture in its place in political economy. Cheltenham: Edward Elgar Publishing.

Thompson J, Bissell P, Cooper C, Armitage CJ and Barber R. (2012) Credibility and the 'professionalized' lay expert: reflections on the dilemmas and opportunities of public involvement in health research. Health 16:(6): 602-618.

Tritter JQ and McCallum A (2006) The snakes and ladders of user involvement: moving beyond Arnstein. Health Policy; 76(2):156-168.

Willis P and Trondman M. (2000) “Manifesto for Ethnography” Ethnography 1(1)5-16.

Pam Carter has research interests in health, wellbeing and social justice that derive from experience of working in disadvantaged areas in the field of community health development for local Government and the NHS. Of particular interest is how language, as well as mundane and apparently benign practices are used as a means to govern and control. Her first academic article won the 2012 Herbert Gottweis prize. She has published articles covering themes of patient and public involvement in health, policy implementation, project 
management, governance and governmentality. Her most recent articles are: Carter P. (2016) Time tactics: project managing policy implementation in a network. Time \& Society and Carter P. (2016) Governing spaces: a multi-sited ethnography of governing welfare reform at close range and at a distance Critical Policy Studies

Address: Department of Health Sciences, University of Leicester, University Road, Leicester, LE1 7RH

Email:pc216@le.ac.uk

Graham Martin is Professor of Health Organisation and Policy in the Social Science Applied to Healthcare Improvement Research (SAPPHIRE) Group, Department of Health Sciences, University of Leicester. His research interests include healthcare reorganisation, professionalism in changing organisational contexts, and service user involvement. His work has been published in journals across the fields of medical sociology, health policy and public administration. His most recent articles include: Martin GP, Kocman D, Stephens T, Peden CJ and Pearse RM. (2017) Pathways to professionalism? Quality improvement, care pathways, and the interplay of standardisation and clinical autonomy. Sociology of Health \& Illness and Martin, G, Currie G, Weaver S, Finn R and McDonald R (2016) Institutional Complexity and Individual Responses: Delineating the Boundaries of Partial Autonomy. Organization Studies. 